\title{
Analisis Dan Desain Rantai Pasok Kakao Berbasis Blockchain
}

\author{
Dian Ardifah Iswari ${ }^{1}$, Yandra Arkeman ${ }^{2}$, Muslich $^{3}$ \\ ${ }^{1}$ Mahasiswa Pascasarjana Program Studi Teknik Industri Pertanian, Fakultas Teknologi Pertanian, Institut Pertanian Bogor, \\ Jalan Lingkar Akademik, Babakan, Kecamatan Dramaga, Kabupaten Bogor, Jawa Barat, Kode Pos 16680 \\ E-mail: dianardifahiswari2@gmail.com \\ ${ }^{2}$ Mahasiswa Pascasarjana Program Studi Teknik Industri Pertanian, Fakultas Teknologi Pertanian, Institut Pertanian Bogor, \\ Jalan Lingkar Akademik, Babakan, Kecamatan Dramaga, Kabupaten Bogor, Jawa Barat, Kode Pos 16680 \\ E-mail: yandrarkeman@gmail.com \\ ${ }^{3}$ Mahasiswa Pascasarjana Program Studi Teknik Industri Pertanian, Fakultas Teknologi Pertanian, Institut Pertanian Bogor, \\ Jalan Lingkar Akademik, Babakan, Kecamatan Dramaga, Kabupaten Bogor, Jawa Barat, Kode Pos 16680 \\ E-mail: muslichmas@yahoo.com
}

\begin{abstract}
The supply chain in the 4.0 era wanted consumers to be closer to producers. Problems that occur in the supply chain are supply chain information flow is still long, there is no transparency, marketing coverage is less extensive, and documentation of activities is not good. The purpose of this study is to analyze the condition of the Kelompok Tani $X$ cocoa supply chain and to identify the attributes of the blockchain based group cocoa supply chain farmers. The method used is the System Development Life Cycle (SDLC) and Unified Modelling Languange. The results obtained are that the supply chain information flow in the $\mathrm{X}$ farmer group is still overlapping, and has not been systematic. Actors consist of farmers, farmer leaders, processing factories (Kelompok Tani $\mathrm{X}$ ), and retailers. Activities that occur are signing up, logging in, filling content, transactions, shipping, validation, and returning goods. The conclusion is the supply chain activities of the Kelompok Tani $\mathrm{X}$ have not been documented. The blockchain system that is designed is adjusted to the situation, so it is expected to be able to make the administration and documentation system better.
\end{abstract}

Keywords -: Agroindustry 4.0; supply chain; system development life cycle; transparency; unified modelling languange.

\section{PENDAhuluaN}

Kakao (Theobroma cocoa) merupakan tanaman yang berasal dari Amerika latin. Kakao masuk di Indonesia pada zaman penjajahan Belanda. Persebaran perkebunan kakao terbesar di Indonesia yaitu Sulawesi Tengah, Sulawesi Tenggara, Sulawesi Selatan, Sumatera Barat, Sulawesi Barat, dan Aceh. Daerah penghasil kakao tertinggi di Indonesia antara lain Sulawesi Tengah, Sulawesi Tenggara, Sulawesi Selatan, Sulawesi Barat, Sumatera Barat, Lampung, Aceh, dan Jawa Timur. Produksi kakao Indonesia sebesar 657.050 ton, ekspor sebesar 354.880 ton, dan impor sebesar 270.172 ton pada tahun 2017 (BPS, 2017). Berdasarkan data dari BPS, industri pengolahan cokelat dalam negeri dapat dikatakan bagus hal ini dapat dilihat dari nilai ekspor kakao terbesar dalam bentuk lemak kakao sebesar 135.875 ton, tepung kakao tanpa tambahan gula/pemanis lainnya 80.071 ton, pasta kakao sebesar 65.711 ton, dan biji kakao 25.099 ton. Impor kakao terbesar dalam bentuk biji kakao sebesar 226.613 ton, tepung kakao tanpa tambahan gula/pemanis lainnya sebesar 19.562 ton, olahan makanan sebesar 6.120 ton (BPS, 2017).

Dalam peredaran kakao tentunya tidak terlepas dari adanya rantai pasok. Rantai pasok merupakan kegiatan perencanaan, pewujudan, dan pengendalian efisiensi dan aktivitas aliran dan penyimpanan barang dan jasa serta informasi terkait produsen hingga konsumen (Arif, 2018). Manajemen rantai pasokan adalah sebuah sistem yang melibatkan proses produksi, pengiriman, penyimpanan, distribusi, dan penjualan produk dalam rangka memenuhi permintaan akan produk tersebut rantai pasokan didalamnya termasuk seluruh proses dan kegiatan yang terlibat didalam penyampaian produk tersebut sampai ke tangan pemakai konsumen (Wuwung, 2013).

Seiring perkembangan zaman rantai pasok pun mengalami perubahan sebagai dampak dari revolusi industri. Revolusi industri 1.0 ditandai dengan adanya mesin uap (Agtech, 2019). Pada rantai pasok revolusi industri mempengaruhi pada bidang transportasi serta proses produksi coklat. Revolusi industri 2.0 ditandai dengan munculnya lini produksi dan listrik (Baenanda, 2019). Pada rantai pasok mempengaruhi pada proses budidaya tanaman serta penggunaan listrik untuk mesin coanching pada proses produksi coklat (Becket, 2008). Revolusi industri 3.0 ditandai dengan masuknya era digitalisasi (Baenanda, 2019). Pada rantai pasok mempengaruhi pada bidang mendeteksi curah hujan untuk penanganan tanaman kakao, mesin-mesin produksi otomatis untuk pengolahan cokelat, penggunaan komputer untuk arsip data penjualan dan produksi. Pada saat ini yaitu era revolusi industri 4.0 yang ditandai adanya sistem cerdas (Baendanda, 2019). Pada rantai pasok era 4.0 memiliki tujuan untuk membawa konsumen lebih dekat dengan petani ataupun perusahaan pertanian.

Blockhain adalah salah satu hasil teknologi pada era 4.0 ini, dimana teknologi blockchain dapat didefinisikan sebagai buku besar terdistribusi yang melacak setiap aktivitas dalam rantai blok, dimana setiap catatan aktivitas tersebut adalah aktivitas yang telah divalidasi (Bogart \& Rice, 2015). Selain itu melalui penerapan blockchain pada rantai pasokan mampu merampingkan jaringan rantai pasok, membangun kepercayaan antar stakeholder, memperkuat rantai pasokan (Light, 2017). 
Website : http://agritek.unmermadiun.ac.id/index.php/agritek

Kelompok Tani X merupakan kelompok tani yang mulai fokus menanam kakao pada tahun 2011 dan mulai memproduksi produk hilir pada tahun 2017. Adanya proses penanaman kakao hingga produksi produk hilir kakao pada Kelompok Tani X secara tidak langsung membentuk suatu sistem rantai pasokan, dimana sistem rantai pasok yang ada terdiri dari petani, ketua tani, pabrik pengolah, retail, dan konsumen. Rantai pasok kakao Kelompok Tani X masih memiliki beberapa permasalahan yaitu sistem komunikasi dan informasi yang panjang, ketidakpercayaan antar stakeholder, sistem dokumentasi yang kurang baik, serta akses pemasaran yang kurang luas. Penerapan blockchain pada rantai pasok kakao di Kelompok Tani X diharapkan mampu mengatasi permasalahan yang terjadi. Tujuan pada penelitian ini yaitu menganalisis kondisi rantai pasok kakao Kelompok Tani X dan mengidentifikasi atribut penyusun rantai pasok kakao Kelompok Tani X berbasis blockchain

\section{METODE PENELITIAN}

Dalam pengembangan sistem rantai pasok kakao berbasis blockchain ini digunakan system development life cycle (SDLC). SDLC merupakan proses pembuatan dan pengubahan sistem serta model dan metodologi yang digunakan untuk mengembangkan sistem tersebut (Susanto \& Andriana, 2016). Adapun tahapan penelitian dapat dilihat pada Gambar 1.

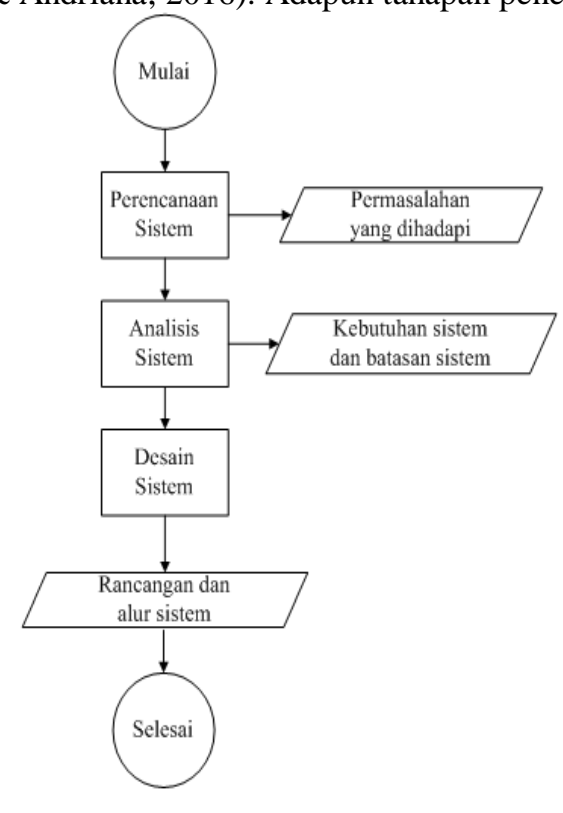

Gambar 1. Tahapan Penelitian

\section{III.HASIL DAN PEMBAHASAN}

\section{A. Gambaran Umum Perusahaan}

Kelompok Tani X merupakan industri yang bergerak dibidang pengolahan kakao dan wisata desa. Kelompok Tani X terletak di Kabupaten Mojokerto. Pada mulanya kelompok tani ini bergerak pada bidang wisata desa dan pada tahun 2011 Kelompok Tani X mulai melebarkan usaha dengan bergerak pada usaha coklat. Pada saat ini kelompok Tani X memiliki jumlah anggota petani coklat kurang lebih 1337 petani yang dibawahi oleh 21 ketua tani. Total luas lahan yang dimiliki oleh Kelompok Tani X sebesar 447 ha, dengan luasan tersebut mampu menghasilkan biji coklat kurang lebih 1609,2 ton/tahun.

Pada tahun 2018, Kelompok Tani X mulai mengolah biji kakao untuk dijadikan produk hilir. Kapasitas terpasang pabrik pengolahan kakao Kelompok Tani X sebesar 2 kwintal/hari. Kelompok Tani X mengolah biji kakaonya menjadi sekitar 50 jenis produk, yang dipasarkan ke warga sekitar kelompok tani

Alur rantai pasok biji kakao di Kelompok Tani X dimulai dari petani, ketua tani, pabrik pengolah, retailer, dan konsumen. Petani berperan dalam menghasilkan biji kakao yang digunakan untuk pabrik memproduksi cokelat. Ketua tani berperan dalam mengumpulkan biji kakao yang dihasilkan oleh petani. Pabrik pengolah berperan dalam memproduksi olahan cokelat. Retailer berperan dalam menyalurkan hasil olahan cokelat kepada konsumen. Dalam rantai pasok ini terdapat tiga aliran yaitu material, informasi, dan finansial. Alur rantai pasok kakao Kelompok Tani X dapat dilihat pada Gambar 2.

\section{B. Perencanaan Sistem}

Sistem blockchain yang dibangun ditujukan untuk digunakan oleh setiap anggota yang ada di dalam rantai pasok kakao. Sistem ini digunakan untuk mempermudah aliran informasi yang ada di dalam rantai pasok kakao, mempermudah 
Website : http://agritek.unmermadiun.ac.id/index.php/agritek

pendokumentasian seluruh aktivitas, memudahkan perhitungan total harga kakao, serta memudahkan proses pembayaran. Sistem ini dibangun dengan menggunakan bahasa pemrograman java dengan sistem database yang digunakan yaitu oracle.

\section{Analisis Sistem}

Dalam mendesain sistem, menganalisis kebutuhan merupakan hal pertama yang perlu dilakukan. Analisis kebutuhan dilakukan untuk menentukan kebutuhan spesifik sistem yang terdiri dari output yang harus dihasilkan, input yang diperlukan untuk menghasilkan output, operasi yang dilakukan untuk menghasilkan output, dan sumberdaya yang diperlukan untuk membuat sistem berjalan dan menghasilkan output (Kristanto, 2018). Analisis kebutuhan sistem dapat dianalisis menggunakan diagram input-output dimana melalui diagram ini dapat diidentifikasi input yang diperlukan, ouput yang akan dihasilkan, sumberdaya yang dibutuhkan, aktor yang berada di dalam sistem, tujuan dari sistem, dan kendala-kendala yang dihadapi oleh sistem. Analisis kebutuhan sistem blockchain untuk rantai pasok kakaodapat dilihat pada Gambar 3.

Input yang diperlukan pada sistem ini yaitu identitas para stakeholder yang terdiri dari petani, ketua tani, pabrik, dan retailer, spesifikasi beserta harga produk yang terdiri dari biji kakao dan produk-produk cokelat olahan, kontrak yang berlaku dalam sistem, dan bukti pembayaran. Stakeholder yang ada dalam sistem yaitu petani, ketua tani, pabrik, dan retailer. Proses yang terjadi yaitu pengelompokan, perhitungan, pembayaran, publikasi, validasi. Sumberdaya yang dibutuhkan oleh sistem yaitu jaringan internet. Tujuan dari sistem ini yaitu mendokumentasikan proses jual beli menjadi terorganisir, mempermudah pelacakan barang, meningkatkan kepercayaan, dan menjadi sumber proses evaluasi. Kendala yang dihadapi adalah kemampuan stakeholder yang rendah untuk menggunakan sistem baru, stakeholder tidak memiliki email dan handphone, serta akses internet yang tidak merata terutama di daerah perkebunan dan pedesaan. Output sistem blockchain adalah kumpulan informasi petani penghasil biji kakao beserta spesifikasi dan harga, kumpulan informasi produk olahan coklat beserta harga, informasi keberadaan barang, informasi jadwal pengambilan biji kakao, informasi pengiriman produk coklat, informasi ketersediaan produk, dan informasi pembayaran produk.

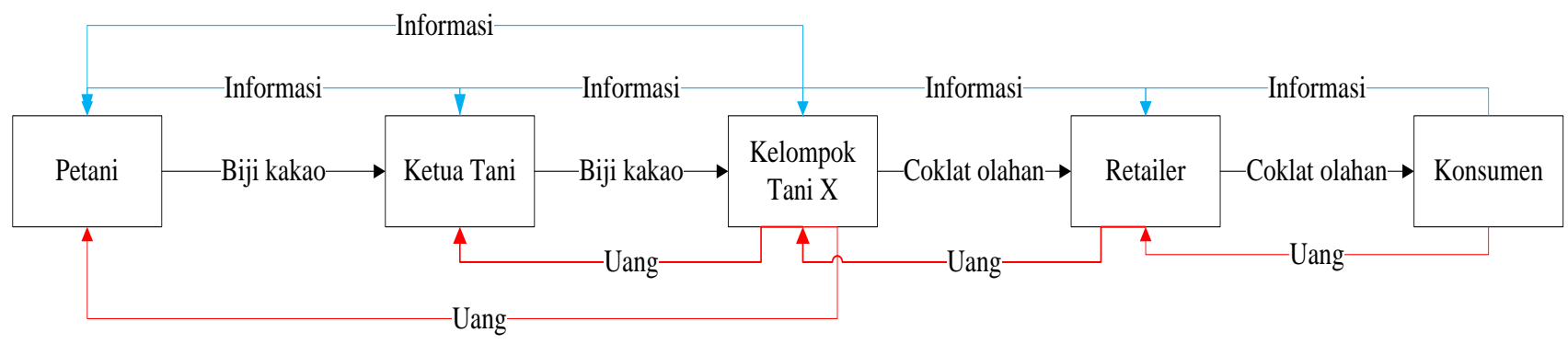

Gambar 2. Alur Rantai Pasok Kakao Kelompok Tani X

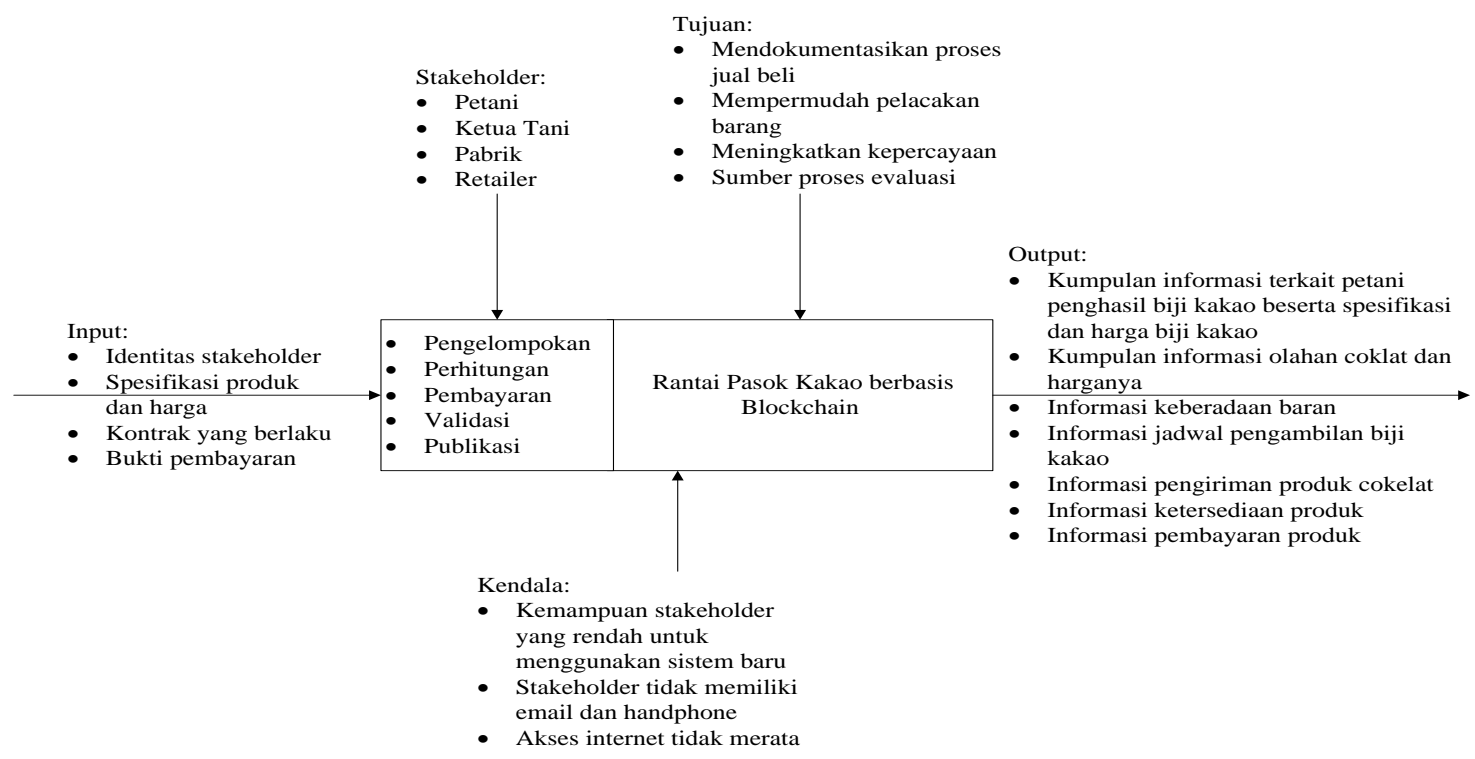

Gambar 3. Analisis Kebutuhan Sistem Rantai Pasok Kakao Berbasis Blockchain

\section{Desain Sistem}

Proses selanjutnya setelah menentukan kebutuhan sistem yaitu mendesain sistem. Dalam penelitian ini digunakan Unified Modelling Languange untuk memodelkan proses berjalannya sistem blockchain untuk rantai pasok kakao. UML merupakan metode dalam mengembangakan suatu sistem yang berorientasi objek dan alat yang mendukung untuk mengembangkan suatu 
Website : http://agritek.unmermadiun.ac.id/index.php/agritek

sistem. UML merupakan bahasa spesifikasi standar yang digunakan untuk mendokumentasikan, menspesifikasikan, dan membangun suatu perangkat lunak (Gata dan Gata, 2013). Unified modelling languange memiliki 10 jenis diagram, dalam penelitian ini digunakan dua jenis diagram yaitu use case diagram dan activity diagram.

1. Use Case Diagram

Use case diagram merupakan pemodelan untuk mengidentifikasi perilaku dari suatu sistem yang akan dibuat (Hendini, 2016). Use case diagram menggambarkan siapa saja pengguna dalam sistem serta apa saja yang dapat dilakukan pengguna kepada sistem. Aktor yang terlibat dalam use case diagram memiliki dua karakteristik yaitu aktor di luar sistem yang sedang dikembangkan dan aktor yang berinteraksi dengan sistem yang dikembangkan (Nugroho, 2009). Dalam pembuatan sistem ini diambil sudut pandang sebagai kelompok tani X dimana kelompok tani $\mathrm{X}$ berperan sebagai pabrik. Petani dan ketua tani merupakan supplier bagi pabrik dan retailer berperan sebagai konsumen produk coklat olahan pabrik untuk dijual kembali. Use case diagram dapat dilihat pada Gambar 4. Dalam sistem ini semua stakeholder terkait harus melakukan proses pendaftaran atau sign up terlebih dahulu. Proses sign up ini penting untuk dilakukan agar dapat memiliki akses ke dalam sistem. Proses selanjutnya yaitu $\log$ in atau masuk ke dalam sistem. Pada saat proses $\log$ in, stakeholder akan diarahkan untuk mengisi konten mengenai produk yang mereka jual. Petani akan mengisi kontennya dengan varian-varian biji kakao yang dijual, sedangkan pabrikdan retailer akan mengisi kontennya dengan hasil olahan coklat yang telah diproduksi. Proses selanjutnya yaitu proses terjadinya transaksi. Pada Gambar 4 dicontohkan adanya proses transaksi oleh pabrik dengan petani. Pembelian biji kakao oleh pabrik kepada petani melalui ketua tani. Meskipun sistem telah berjalan secara online, namun proses pengumpulan biji kakao tetap dilakukan di ketua tani. Hal ini difungsikan agar biaya transportasi biji kakao ke pabrik lebih rendah dibandingkan harus diambil pada petani satu per satu. Oleh karena itu proses pengiriman biji kakao pun terjadi antara petani, ketua tani, dan pabrik.

Proses selanjutnya yaitu proses validasi. Pada saat barang telah sampai di pabrik, maka pabrik akan melakukan pengecekkan apakah barang yang sampai telah sesuai. Apabila barang telah sesuai dengan kriteria yang telah dicantumkan di sistem maka pabrik dapat melakukan validasi, sedangkan apabila barang tidak sesuai maka pabrik dapat melakukan pengembalian barang. Proses ini juga serupa dengan proses transaksi antara pabrik dengan retailer.

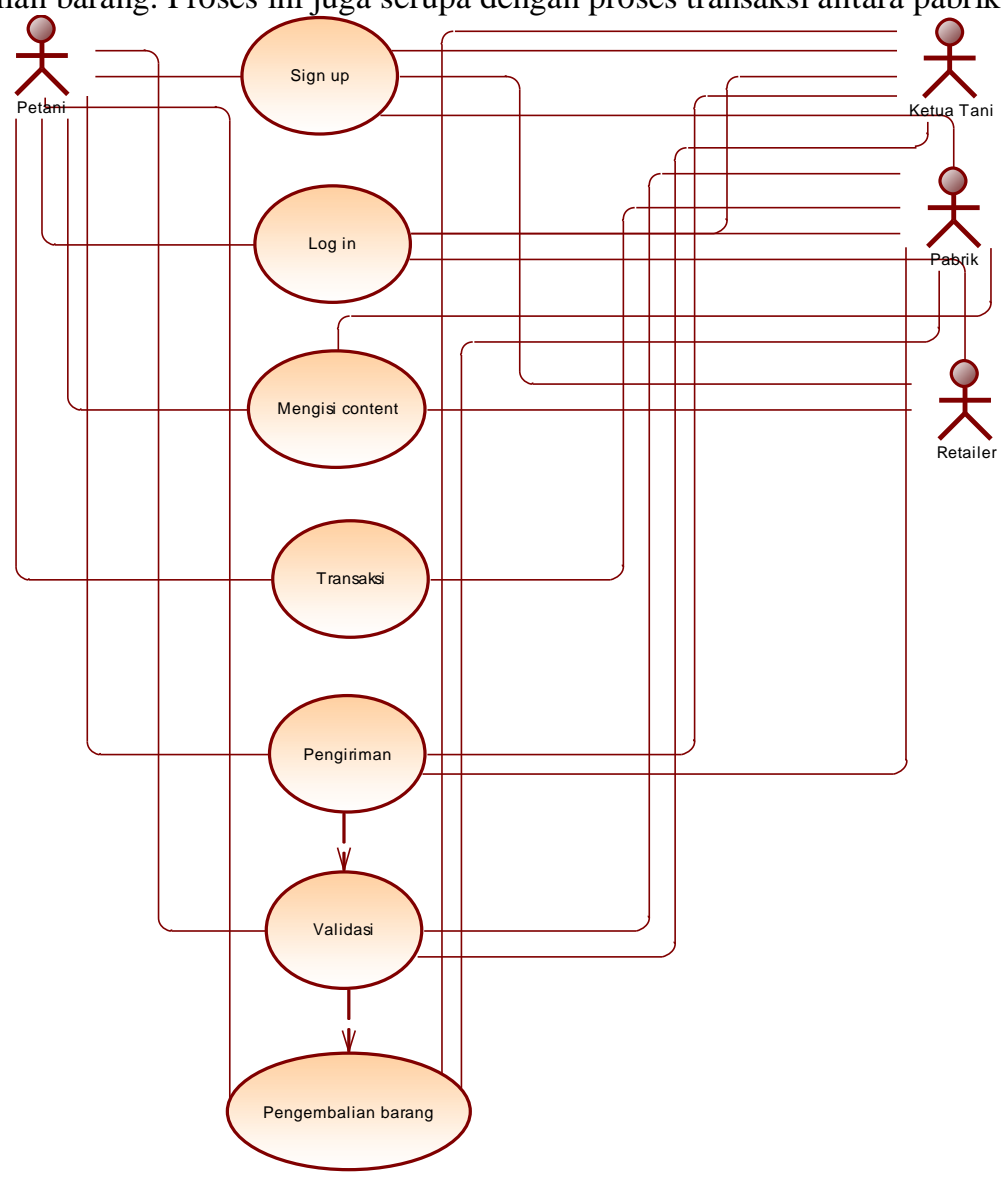

2. Activity Diagram

Activity diagram merupakan diagram yang menggambarkan sifat dinamis secara alamiah sebuah sistem dala bentuk model aliran dan kontrol aktivitas ke aktivitas. Perbedaan activity diagram dan use case diagram yaitu activity diagram menggambarkan bagaimana suatu proses berjalan, sedangkan use case diagram menggambarkan bagaimana aktor menggunakan sistem untuk melakukan aktivitas. Pada activity diagram terdapat decision yang digunakan untuk 
Website : http://agritek.unmermadiun.ac.id/index.php/agritek

menggambarkan perilaku pada suatu kondisi tertentu (Dharwiyanti dan Wahono, 2003). Keuntungan dari penggunaan activity diagram yaitu memudahkan untuk memahami scenario yang berjalan pada sistem (Nugroho, 2009). Activity diagram digunakan untuk memodelkan diagram alir kerja atau proses bisnis dan operasi-operasi secara internal. Pada diagram ini akan digambarkan proses-proses yang lebih detail dibandingkan pada use case diagram. Activity diagram sistem blockchain untuk rantai pasok kakao dapat dilihat pada Gambar 5.

Aktivitas yang dilakukan pertama kali yaitu sign up atau pendaftaran. Pada proses sign up, pengguna akan diminta mengisi identitas seperti nama, alamat, email, dan nomor telepon. Proses selanjutnya yaitu pengguna akan mensubmit identitas dan menerima konfirmasi email. Proses selanjutnya yaitu log in. Pada proses log in, pengguna akan mengisikan ID dan password, apabila sesuai maka pengguna dapat masuk ke dalam sistem dan jika tidak sesuai maka pengguna harus mengisi ulang ID dan password. Proses selanjutnya yaitu pengisian konten, pada proses pengisian konten ini pengguna akan mengisi terkait nama produk, foto produk, dan harga produk. Selain itu juga ditambahkan terkait metode pembayaran yang diterima dan proses pengirimannya. Tahap terakhir pada pengisian konten yaitu pembuatan kategori produk.

Proses selanjutnya yaitu proses berjalannya transaksi. Pengguna pada awalnya melakukan pemilihan produk, setelah melakukan pemilihan produk pengguna akan mengisikan alamat pengantaran, memilih metode pengiriman, dan memilih metode pembayaran. Proses selanjutnya yaitu pengguna akan melakukan pembayaran sesuai jangka waktu yang ditetapkan. Pengguna yang telah melakukan pembayaran dapat melakukan konfirmasi pembayaran dengan mengupload bukti pembayaran, apabila pembayaran sukses maka invoice akan diterbitkan. Apabila waktu telah habis dan pengguna tidak melakukan pembayaran maka transaksi dibatalkan dan pengguna harus mengisi ulang metode pembayaran.

Pada aktivitas pengiriman, pada saat adanya transaksi dan telah ditentukan alamat pengiriman maka akan terjadi sub aktivitas yaitu pengecekan destinasi pengiriman sehingga bisa ditentukan biaya pengirimannya. Proses selanjutnya saat invoice telah terbit maka pengiriman akan dilakukan. Pada saat barang telah sampai, maka akan dilakukan proses pemeriksaan pesanan. Apabila barang yang datang sesuai maka pengguna dapat mengkonfirmasi telah diterima, maka dana akan dikirimkan kepada penjual, dan pengguna akan memberikan review. Apabila barang yang datang tidak sesuai maka pengguna dapat melakukan aktivitas pengembalian barang. Pengguna akan diminta untuk mengisikan alasan pengembalian barang, apabila alasan disetujui maka pengguna dapat mengirimkan barang ke penjual lagi, sedangkan jika tidak disetujui maka pengguna harus mengkonfirmasi penerimaan barang dan memberikan review. 


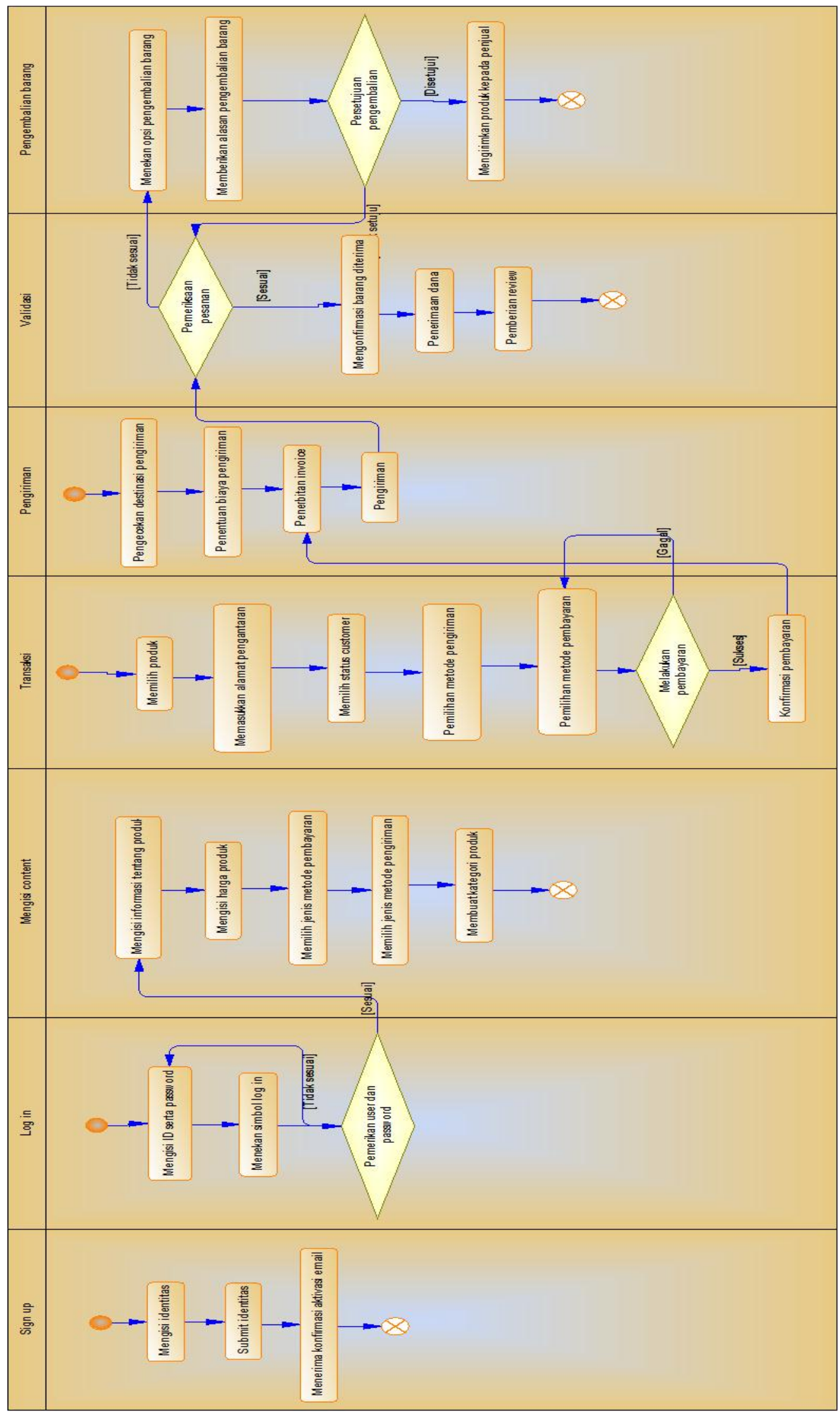

Gambar 5. Activity diagram sistem blockchain untuk rantai pasok kakao 
Website : http://agritek.unmermadiun.ac.id/index.php/agritek

\section{IV.KESIMPULAN}

Kesimpulan yang dapat diambil pada penelitian ini yaitu:

1. Kondisi rantai pasok kakao yang berada di Kelompok Tani X terdiri dari petani, ketua tani, pabrik pengolah, dan retailer. Alur informasi terjadi saling tumpang tindih karena harus melalui wakil manajer terlebih dahulu sebelum diteruskan kepada pihak lainnya. Aktivitas yang terjadi di dalam rantai pasok kakao Kelompok Tani X antara lain produksi biji kakao, pengiriman biji kakao, pembayaran biji kakao, pembelian biji kakao, pengolahan biji kakao, dan penjualan hasil olahan cokelat. Aktivitas ini belum terdokumentasikan dengan baik.

2. Sistem blockchain dapat diaplikasikan ke dalam jaringan rantai pasok, sehingga alur informasi yang sebelumnya tumpang tindih dapat lebih efisien dari sebelumnya. Selain itu, dengan adanya sistem blockchain diharapkan mampu membuat sistem administrasi dan dokumentasi menjadi lebih baik.

\section{UCAPAN TERIMAKASIH}

Ucapan terimakasih saya sampaikan kepada kelompok Tani X yang telah berkenan membantu penelitian ini sehingga penelitian ini berjalan dengan lancar, serta kedua pembimbing saya Bapak Yandra Arkeman dan Bapak Muslich yang telah meluangkan waktunya untuk memberikan saran sehingga penelitian ini dapat diselesaikan.

\section{VI.DAFTAR PUSTAKA}

Arif, M. 2018. Supply Chain Management. Budi Utama, Yogyakarta.

Badan Pusat Statistika. 2017. Statistik Kakao Indonesia 2017. Badan Pusat Statistika, Jakarta.

Baenanda, L. 2019, Mengenal Lebih Jauh Revolusi Industri 4.0, disitasi pada 7 Juli 2019, <http://binus.ac.id/knowledge/2019/05/mengenal-lebih-jauh-revolusiindustri-4-0/>.

Becket, S. T. 2009. The Science of Chocolate $2^{\text {nd }}$ Edition. RSC Publishing, Cambridge.

Bogart, S., dan Kerry, R. 2015. The Blockchain Report: Welcome to the Internet of Value. Needham \& Company LLC, Newyork.

Dharwiyanti, S. dan Wahono, R. S. 2003. Pengantar Unified Modelling Languange (UML). Ilmu Komputer.

Gata, W., dan Grace, G. 2013. Sukses Membangun Aplikasi Penjualan dengan Java. Elex Media Komputindo, Jakarta

Hendini, A. 2016. Pemodelan UML Sistem Informasi Monitoring Penjualan dan Stok Barang (Studi Kasus: Distro Zhezha Pontianak). J. Khatulistiwa Informatika, 4(2): 107-116.

Kristanto, A. 2018. Perancangan Sistem Informasi dan Aplikasinya (Edisi Revisi). Gava Media, Jakarta.

Light, S. 2017. Rantai Pasokan yang Kuat dengan Teknologi Blockchain, disitasi pada 23 Januari 2019<https://medium.com/@ sky02676/rantai-pasokan-yangkuat-dengan-teknologi-blockchain-1d740aecd7ea>.

Nugroho, A. 2009. Rekayasa Perangkat Lunak menggunakan UML dan Java. Andi Offset, Yogyakarta.

Susanto, R, dan Anna, D. A. 2016. Perbandingan Model Waterfall dan Protyping untuk Pengembangan Sistem. Majalah Ilmiah Unikom, 14(1): 41-46.

Wuwung, S. C. 2013. Manajemen Rantai Pasokan Produk Cengkeh pada Desa Wawona Minahasa Selatan. J. Emba, 1(3): 230-238. 